\title{
Aspectos hematológicos de catetos (Tayassu tajacu) mantidos em cativeiro ${ }^{1}$
}

\author{
Aline M.B. Almeida ${ }^{2}$, Sergio L.G. Nogueira-Filho ${ }^{3}$, Selene S.C. Nogueira ${ }^{4}$ \\ e Alexandre D. Munhoz ${ }^{3^{*}}$
}

\begin{abstract}
Almeida A.M.B., Nogueira-Filho S.L.G, Nogueira S.S.C. \& Munhoz A.D. 2011. [Hematologic aspects of collared peccary (Tayassu tajacu) in captivity.] Aspectos hematológicos de catetos (Tayassu tajacu) mantidos em cativeiro. Pesquisa Veterinária Brasileira 31(2):173-177. Setor de Patologia Clínica Veterinária, Faculdade de Veterinária, Universidade Estadual de Santa Cruz, BR 16, Ilhéus, Bahia, BA 45650-000, Brazil. Email: munhoz@uesc.br

The aim of the study was to determine the blood values for the Tayassu tajacu (collared peccary) in captivity. Twenty-six collared peccary, being twenty-one adults (13 males and 8 females) and five young ( 3 males and 2 females) were maintained at the Experimental Farm of Almada and the Laboratory of Applied Ethology, belonging to the University Estadual of the Santa Cruz, Ilheus, Bahia, Brazil. Blood samples were collected from the cephalic vein to perform the complete blood count. Statistical analysis was performed using the Student's t-test, with a significance level of $95 \%$. There was no significant difference from animals maintained in stalls or pickets, however there was a higher value of total plasma protein in males $(p<0,05)$. When comparing adult animals with young animals, we observed differences in the packed cell volume $(p<0,05)$ and a reverse relationship between mature neutrophils/lymphocytes, with a predominance of mature neutrophils $(46,8 \%)$ on lymphocytes (45\%) for young animals. Regarding the measurement of the cells was observed similarity to that described for cows, cats and horses. These results could support new studies, as well as future interpretations in healthy or sick animals, with attention how to handle the management of animals, weather and especially the form of restraint and type of population in what these studies are conducted.
\end{abstract}

INDEX TERMS: Peccary, Tayassu tajacu, measurement cell, normal blood values.

RESUMO.- Este estudo teve por objetivo determinar os valores hematológicos de Tayassu tajacu (catetos) mantidos em cativeiro. Foram utilizados 26 catetos, sendo 21 adultos (13 machos e 8 fêmeas) e 5 filhotes (três machos e duas fêmeas), mantidos na Fazenda Experimental do Almada e no Laboratório de Etologia Aplicada, pertencente à Universidade Estadual de Santa Cruz, Ilheus, BA. Amostras de sangue foram colhidas, da veia cefálica, para realização

\footnotetext{
${ }^{1}$ Recebido em 18 de dezembro de 2009.

Aceito para publicação em 26 de outubro de 2010.

${ }^{2}$ Médica Veterinária, Residente em Patologia Clínica da UnB, Campus Universitário Darcy Ribeiro, Via L4, Asa Norte, Brasília, DF 70910900. E-mail: aline_melgaco@yahoo.com.br

${ }^{3}$ Departamento de Ciências Agrárias e Ambientais, UESC, Rodovia Ilhéus-Itabuna, Km 16, Ilhéus, BA 45650-000, Brasil. *Autor para correspondência: munhoz@uesc.br

${ }^{4}$ Departamento de Ciências Biológicas, UESC, Rodovia IlhéusItabuna, Km 16, Ilhéus, BA.
}

dos hemogramas. A análise estatística foi obtida por meio do teste "t" de Student, com nível de significância de 95\%. Na comparação entre os animais instalados em baias e piquetes não foi observada diferença significativa, no entanto observou-se um maior valor da proteína plasmática total nos machos $(\mathrm{p}<0,05)$. Ao se comparar animais adultos com jovens, observou-se diferença no valor do volume globular $(p<0,05)$ e uma relação neutrófilo segmentado/linfócito inversa, com predomínio dos neutrófilos segmentados sobre os linfócitos nos animais jovens. Em relação à mensuração das células observou-se semelhança ao descrito para vacas, gato e cavalos. Estes resultados poderão subsidiar novos estudos, assim como futuras interpretações em animais hígidos ou doentes, com atenção às condições de manejo, clima e principalmente forma de contenção e tipo de população em que os estudos são realizados.

TERMOS DE INDEXAÇÃO: Cateto, Tayassu tajacu, hemograma, mensuração de células. 


\section{INTRODUÇÃO}

A fauna silvestre tem sido utilizada há décadas como fonte de proteína animal pelas populações indígenas e rurais no interior do Brasil. Apesar das legislações proibitivas, a caça tem sido o meio utilizado para esta exploração (Nogueira-Filho \& Lavorenti 1995). Dentre as espécies silvestres da fauna brasileira que vêm demonstrando condições favoráveis à adaptação em cativeiro e conseqüentemente a exploração comercial, destaca-se o cateto, Tayassu tajacu (Linnaeus 1758), pertencente à família Tayassuidae (Batista et al. 2008).

Além de servir como fonte de proteína para subsistência, há a possibilidade de comercialização de matrizes e reprodutores, da própria carne e do couro no mercado internacional (Nogueira-Filho \& Lavorenti 1995).

A hematologia de animais selvagens, especialmente os da fauna brasileira, ainda é um campo de trabalho científico pouco explorado, sendo necessários estudos para que se possa chegar a um nível adequado de compreensão de suas particularidades (Garcia Navarro \& Pachaly 1994).

No Brasil os estudos realizados com catetos, geralmente visam a avaliação do seu comportamento e de práticas de manejo (Nogueira \& Lavorenti 1995, Batista et al. 2008) sendo restrito os trabalhos que investigam o perfil hematológico desses animais em nosso território. Esta carência faz com que seja utilizado como parâmetro estudos realizados em outros países (Lochmiller et al. 1985a, Aparício 2004, Galvez et al. 2004) sob condições, que diferem das nossas.

A colheita de sangue nessa espécie é aparentemente difícil, devido às características anatômicas do animal (Lochmiller et al. 1984) como o pequeno calibre da veia cefálica e o difícil acesso da jugular, além disso, a colheita de sangue por meio da veia jugular torna-se perigosa devido à característica agressiva do animal. Contudo uma contenção física adequada pode viabilizar o processo de colheita através da veia cefálica (Furtado \& Kashivakura 2007).

Com base nessas informações a realização deste estudo tem como objetivo a determinação dos parâmetros hematológicos em catetos, mantidos em cativeiros, no Estado da Bahia, Brasil.

\section{MATERIAL E MÉTODOS}

O estudo foi realizado no município de llhéus (Altitude de $47 \mathrm{~m}$; Latitude Sul $14^{\circ} 47^{\prime}$ e Longitude Oeste $39^{\circ} 02^{\prime}$ ), situada no Sul da Bahia. Foram utilizados 26 catetos, sendo 21 adultos (13 machos e oito fêmeas), com peso médio de $30 \mathrm{Kg}$ e cinco filhotes (três machos e duas fêmeas) com idade de dois meses, mantidos na Fazenda Experimental do Almada e no Laboratório de Etologia Aplicada, pertencente à Universidade Estadual de Santa Cruz (UESC), Ilheus, BA. Dos adultos dez eram mantidos em sistema intensivo (baias para suinocultura) e onze em sistema semi-intensivo de criação (piquetes). A alimentação destes animais consistia de ração balanceada de farelo de soja ( $46 \%$ de proteína bruta), farelo de milho, sal mineral de recria e água ad libitum.
A colheita de sangue foi realizada sempre no período da manhã. Os animais foram capturados com auxilio de um puçá, contidos fisicamente, sendo retirado $4 \mathrm{~mL}$ de sangue da veia cefálica, com auxílio de um escalpe $\mathrm{n}^{\circ} \mathbf{1 9}$, acoplado à seringa de $5 \mathrm{~mL}$ contendo EDTA a $10 \%$. O sangue foi acondicionado sob refrigeração e seu processamento realizado no Laboratório de Análise Clínicas Veterinárias da UESC. Para determinação da hematimetria e da leucometria global realizou-se a contagem manual na câmara de Neubauer. A determinação da concentração de hemoglobina, volume globular, proteína plasmática total, fibrinogênio e índices hematimétricos foi obtida segundo Jain (1993) e Lasser \& Weiser (2006). A contagem diferencial de leucócitos foi realizada por meio de esfregaços sanguíneos corados pelo método Panótico Rápido e posteriormente analisados ao microscópio óptico em aumento de 1000x.

Em cada esfregaço dos animais adultos, pelo menos cinco hemácias e cinco leucócitos de cada tipo foram microfotografados com auxílio de uma câmera digital de vídeo Olympus ${ }^{\mathrm{TM}}$ Mod. DP-72. X2, acoplada ao microscópio trinocular BX60 Olympus $^{\mathrm{TM}}$ e mensuradas com o auxílio do software image pro Express 6.0.

Os animais foram categorizados segundo sexo, idade e habitat e os parâmetros analisados através do teste "T" de Student, com nível de significância de 95\%.

\section{RESULTADOS}

Foi encontrada diferença significativa $(p<0,05)$ na comparação realizada entre animais adultos e jovens no volume globular e na contagem diferencial de linfócitos, neutrófilos segmentados e eosinófilos (Quadro 1).

Quadro 1. Média e desvio-padrão de variáveis hematológicas, concentração da proteína plasmática total e fibrinogênio de animais jovens e adultos, da espécie Tayassu tajacu mantidos em cativeiro

\begin{tabular}{|c|c|c|c|}
\hline Variável & $\begin{array}{c}\text { Jovem } \\
(\mathrm{n}=5)\end{array}$ & $\begin{array}{l}\text { Adulto } \\
(\mathrm{n}=21)\end{array}$ & $\mathrm{P}$ \\
\hline Hemácias $\left(\times 10^{6} / \mu \mathrm{L}\right)$ & $9,70( \pm 1,09)$ & $10,81( \pm 1,52)$ & ns \\
\hline Volume globular (\%) & $48,6( \pm 2,60)$ & $51,85( \pm 3,16)$ & $<0,05$ \\
\hline Hemoglobina (g/dL) & $15,75( \pm 0,44)$ & $17,56( \pm 1,39)$ & ns \\
\hline VCM (fl) & $50,47( \pm 5,00)$ & $48,80( \pm 5,98)$ & ns \\
\hline $\mathrm{CHCM}(\mathrm{g} / \mathrm{dL})$ & $32,46( \pm 1,42)$ & $33,83( \pm 2,18)$ & ns \\
\hline $\mathrm{HCM}(\mathrm{pg})$ & $16,37( \pm 1,65)$ & $17,52( \pm 1,32)$ & ns \\
\hline Proteína (g/dL) & $7,12( \pm 0,17)$ & $8,74( \pm 0,68)$ & ns \\
\hline Fibrinogênio (mg/dL) & $140( \pm 82,15)$ & $157,14( \pm 69,43)$ & ns \\
\hline Leucócitos $\left(x 10^{3} / \mu \mathrm{L}\right)$ & $15,06( \pm 4,20)$ & $12,47( \pm 1,70)$ & ns \\
\hline Segmentado/ $\mu \mathrm{L}$ & $6648( \pm 1877)$ & $7219( \pm 1192)$ & ns \\
\hline Segmentado \% & $46,8( \pm 6,61)$ & $37,28( \pm 9,16)$ & $<0,05$ \\
\hline Neutrófilo bastonete/ $\mu \mathrm{L}$ & $25,2( \pm 50,4)$ & $151,2( \pm 121,14)$ & ns \\
\hline Neutrófilo bastonete \% & $0,33( \pm 0,47)$ & $1,14( \pm 0,96)$ & ns \\
\hline 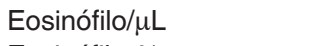 & $1115( \pm 496)$ & $242,85( \pm 208,10)$ & $<0,05$ \\
\hline Eosinófilo \% & $7,2( \pm 2,92)$ & $2,04( \pm 1,74)$ & $<0,05$ \\
\hline 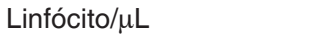 & $6668( \pm 1877)$ & $7228,6( \pm 1192)$ & $<0,05$ \\
\hline Linfócito \% & $45( \pm 7,58)$ & $58,52( \pm 8,05)$ & $<0,05$ \\
\hline 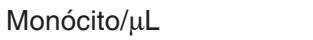 & $109( \pm 69,1)$ & $106,85( \pm 112,52)$ & ns \\
\hline Monócito \% & $1( \pm 0)$ & $1( \pm 0,94)$ & ns \\
\hline 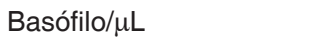 & $0(0 \pm 0)$ & $0(0 \pm 0)$ & ns \\
\hline Basófilo \% & $0( \pm 0)$ & $0( \pm 0)$ & ns \\
\hline
\end{tabular}

$\mathrm{M}=$ Volume globular médio; $\mathrm{HCM}=$ hemoglobina corpuscular média; $\mathrm{CHCM}=$ concentração de hemoglobina corpuscular média; ns = não significativo. 


\begin{tabular}{|c|c|c|c|}
\hline Variável & $\begin{array}{l}\text { Macho } \\
(n=13)\end{array}$ & $\begin{array}{c}\text { Fêmea } \\
(\mathrm{n}=8)\end{array}$ & $P$ \\
\hline Hemácias $x\left(10^{6}\right) / \mu \mathrm{L}$ & $11,16( \pm 1,64)$ & $10,24 \pm 1,18)$ & ns \\
\hline Volume globular (\%) & $52,84( \pm 2,96)$ & $50,25(+-2,96)$ & ns \\
\hline Hemoglobina (g/dL) & $17,70( \pm 1,35)$ & $17,33( \pm 1,35)$ & ns \\
\hline VCM (fl) & $51,01( \pm 6,25)$ & $50,29(+-4,26)$ & 'ns \\
\hline $\mathrm{CHCM}(\mathrm{g} / \mathrm{dL})$ & $34,41( \pm 2,56)$ & $36,01( \pm 0,96)$ & ns \\
\hline $\mathrm{HCM}(p g)$ & $16,62( \pm 2,9)$ & $17,13(+-0,59)$ & ns \\
\hline Proteína Plasmática total $(\mathrm{g} / \mathrm{dL})$ & -) $8,97( \pm 073)$ & $8,20( \pm 0,37)<$ & $<0,05$ \\
\hline Fibrinogênio (mg/dL) & $157,14( \pm 73,19)$ & $170(+-67,08)$ & ns \\
\hline 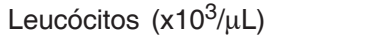 & $11,76( \pm 1,75)$ & $12,27( \pm 2,36)$ & ns \\
\hline Segmentado \% & $37,2( \pm 10,60)$ & $38,8( \pm 14,25)$ & ns \\
\hline Segmentado/ $\mu \mathrm{L}$ & $4884,52( \pm 1574,68)$ & $5032( \pm 2241)$ & ns \\
\hline Neutrófilo bastonete \% & $1( \pm 0,66)$ & $1,6( \pm 0,89)$ & ns \\
\hline Neutrófilo bastonete/ $\mu \mathrm{L}$ & $123,55( \pm 89)$ & $201,34( \pm 119,2)$ & ns \\
\hline Eosinófilo \% & $2,4( \pm 1,34)$ & $2( \pm 2)$ & ns \\
\hline 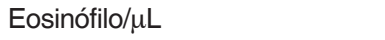 & $270( \pm 189,50)$ & $223,77( \pm-222)$ & ns \\
\hline Linfócito \% & $58,1( \pm 9,37)$ & $56( \pm 12,72)$ & ns \\
\hline 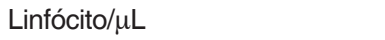 & $7154( \pm 1739)$ & $6822( \pm 1357)$ & ns \\
\hline Monócito \% & $1( \pm 0,66)$ & $1( \pm 0,70)$ & ns \\
\hline Monócito/uL & $127,04( \pm 98,27)$ & $115( \pm 67,47)$ & ns \\
\hline Basófilo \% & $0( \pm 0)$ & $0( \pm 0)$ & ns \\
\hline 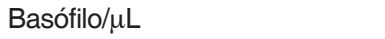 & $0( \pm 0)$ & $0( \pm 0)$ & ns \\
\hline
\end{tabular}

$\mathrm{VCM}=$ Volume globular médio; HCM = hemoglobina corpuscular média; $\mathrm{CHCM}$ = concentração de hemoglobina corpuscular média; ns = não significativo.

Quadro 3. Média e desvio-padrão de variáveis hematológicas, concentração da proteína plasmática total e fibrinogênio de animais adultos instalados em baias e piquetes da espécie Tayassu tajacu, mantidos em cativeiro

\begin{tabular}{|c|c|c|c|}
\hline Variável & $\begin{array}{c}\text { Baia } \\
(n=10)\end{array}$ & $\begin{array}{c}\text { Piquete } \\
(n=11)\end{array}$ & $P$ \\
\hline Hemácias $\left(x 10^{6} / \mu \mathrm{L}\right)$ & $11,15( \pm 1,09)$ & $10,57( \pm 2)$ & ns \\
\hline Volume globular (\%) & $53,42( \pm 3,5)$ & $51,63( \pm 3,78)$ & ns \\
\hline Hemoglobina (g/dL) & $18,13( \pm 1)$ & $17,8( \pm 1,49)$ & ns \\
\hline VCM (fl) & $48,33( \pm 3)$ & $50,33( \pm 8,45)$ & ns \\
\hline $\mathrm{CHCM}(\mathrm{g} / \mathrm{dL})$ & $34,45( \pm 3,08)$ & $35,3( \pm 0,5)$ & ns \\
\hline $\mathrm{HCM}(p g)$ & $16,35( \pm 1,05)$ & $17,35( \pm 3,84)$ & ns \\
\hline Proteína Plasmática Total (g/dL) & $8,68( \pm 1)$ & $8,78( \pm 0,92)$ & ns \\
\hline Fibrinogênio $(\mathrm{mg} / \mathrm{dL})$ & $157,14( \pm 73)$ & $181,25( \pm 53,03)$ & ns \\
\hline 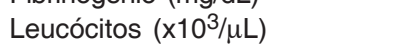 & $11,55( \pm 1,99)$ & $13,92( \pm 1,98)$ & ns \\
\hline Segmentado \% & $36,9( \pm 7,79)$ & $37,63( \pm 10,34)$ & ns \\
\hline Segmentado/ $\mu \mathrm{L}$ & $4457( \pm 1435)$ & $5037( \pm 1692)$ & ns \\
\hline Neutrófilo bastonete \% & $1,1( \pm 0,83)$ & $1,18( \pm 1,07)$ & ns \\
\hline Neutrófilo bastonete/ $\mu \mathrm{L}$ & $130,3( \pm 106,40)$ & $172,1( \pm 136,70)$ & ns \\
\hline Eosinófilo \% & $2,6( \pm 1,68)$ & $1,54( \pm 1,63)$ & ns \\
\hline Eosinófilo/uL & $285,8( \pm 189)$ & $199,9( \pm 227)$ & ns \\
\hline Linfócito \% & $58,2( \pm 6,70)$ & $58,81( \pm 9,19)$ & ns \\
\hline Linfócito/ $\mu \mathrm{L}$ & $6782( \pm 986,67)$ & $7675( \pm 1259)$ & ns \\
\hline Monócito \% & $1,2( \pm 1,16)$ & $0,81( \pm 0,60)$ & ns \\
\hline 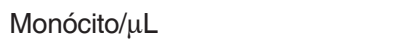 & $107,6( \pm 140)$ & $106,1( \pm 84,37)$ & ns \\
\hline Basófilo \% & $0( \pm 0)$ & $0( \pm 0)$ & ns \\
\hline 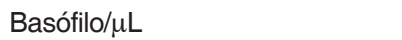 & $0( \pm 0)$ & $0( \pm 0)$ & ns \\
\hline
\end{tabular}

VCM = Volume globular médio; HCM = hemoglobina corpuscular média; $\mathrm{CHCM}$ = concentração de hemoglobina corpuscular média; ns = não significativo.
No que se refere à contagem diferencial de leucócitos, nos animais adultos, pôde-se observar predomínio de linfócitos e neutrófilos segmentados, com uma maior porcentagem média de linfócitos $(58,52 \%)$ em relação aos neutrófilos segmentados (37,28\%) tanto em machos quanto em fêmeas, e nos diferentes sistemas de criação. Verificou-se um menor percentual de monócitos e eosinófilos, e uma ausência de basófilos. Nos filhotes, embora os maiores percentuais também tenham sido de neutrófilos segmentados e os linfócitos, a relação foi inversa, com predomínio médio dos neutrófilos segmentados $(46,8 \%)$ sobre os linfócitos (45\%).

Verificou-se que os valores médios encontrados para o número de eritrócitos, Volume Globular Médio (VGM), Hemoglobina Globular Média (HCM), Concentração de Hemoglobina Globular Média (CHCM), volume globular, concentração de hemoglobina, leucometria global, específica e fibrinogênio foram semelhantes entre machos e fêmeas adultos, a exceção da proteína plasmática total que foi superior no macho $(p<0,05)$ (Quadro 2). Na comparação entre os animais adultos instalados em baias e piquetes não foi observada diferença significativa em nenhum dos parâmetros avaliados (Quadro 3).

Cento e cinco mensurações de cada tipo celular foram realizadas, onde os resultados encontram-se apresentados no Quadro 4.

\section{Quadro 4. Média e desvio-padrão de células sanguíneas mensuradas em animais da espécie Tayassu tajacu mantidos em cativeiro}

\begin{tabular}{lcc}
\hline Células $^{\mathrm{a}}$ & $\mathrm{MD}^{\mathrm{b}}$ & $\mathrm{Md}^{\mathrm{b}}$ \\
\hline Hemácias & $5,73( \pm 0,63)$ & $5,22( \pm 0,67)$ \\
Linfócito & $10,81( \pm 1,24)$ & $8,86( \pm 1,45)$ \\
Eosinófilo & $14,50( \pm 1,29)$ & $12,46( \pm 1,81)$ \\
Monócito & $16,13( \pm 1,50)$ & $15,03( \pm 1,90)$ \\
Neutrófilo segmentado & $13,30( \pm 1,48)$ & $11,84( \pm 1,69)$ \\
Neutrófilo bastonete & $13,51( \pm 1,67)$ & $10,57( \pm 2,19)$
\end{tabular}

a Cento e cinco mensurações por célula sanguínea.

b Valor expresso em micrômetros.

$\mathrm{MD}=$ média do diâmetro maior das células; $\mathrm{Md}=$ média do diâmetro menor das células.

\section{DISCUSSÃO}

As colheitas de sangue foram realizadas no período da manhã com o intuito de não provocar estresse térmico evitando alterações clínicas, que pudessem influenciar os resultados como mencionado por Batista et al. (2008).

Tanto a contenção química quanto a contenção física podem causar alterações nos parâmetros hematológicos em animais (Jain 1993, Batista 2008). Embora a contenção química torne mais fácil a obtenção de amostras sanguíneas em animais silvestres (Jain 1993), optou-se pela contenção física pelo fato dos catetos estarem adaptados ao cativeiro e a captura ser realizada por um tratador experiente, que mantém um convívio diário com os animais, o que miniminiza, os efeitos indesejáveis da captura e contenção.

A média encontrada para proteína foi superior nos ma- 
chos $(p<0,05)$, contudo se assemelha aos valores médios encontrados por outros autores (Lochmiller et al. 1985b, Santos 1999).

Os valores médios no número de eritrócitos de machos e fêmeas foram superiores aos $6,44 \times 10^{6} \mu \mathrm{L}$ encontrados por Lochmiller et al. (1985a), que na sua colheita utilizaram a sedação com quetamina, e similares aos de Santos (1999), Aparício (2004) e Galvez et al. (2004), que realizaram a colheita com contenção física.

Assim, a contenção física poderia suscitar como hipótese uma policitemia pela contração esplênica, contudo algumas evidências descartam esta possibilidade ou pelo menos minimizam seu efeito: 1) a contração do baço tende a aumentar entre $10-15 \%$ o volume do hematócrito depois de uma venopunção (Jain 1993), logo a grande diferença observada não poderia ser em função apenas deste fenômeno; e 2) a comparação com número de neutrófilos e da leucometria global nos estudos de Lochmiller et al. (1985a), Santos (1999), Aparício (2004) e Galvez et al. (2004) evidencia uma ausência de leucocitose com neutrofilia fisiológica (Lasser \& Weiser 2006), que seria esperado quando há um estímulo adrenérgico.

A possibilidade de desidratação e policitemia por hipóxia também são descartadas uma vez que, os valores da proteína plasmática total e altitude em todos os estudos foram semelhantes. Soma-se ao fato que o uso da quetamina na contenção dos animais pode levar a uma diminuição no número de hemácias pela redistribuição destas para o baço e para os tecidos periféricos (Flaiban et al. 2008).

Logo, além da diferença na forma de contenção dos animais, o estudo de Lochmiller et al. (1985a) foi realizado no semi-árido do Texas, enquanto que neste e nos demais estudos ocorreram em clima tropical ou equatorial, desta forma é sensato pensar que fatores como tipo de contenção, população estudada e possivelmente clima possam influenciar nos eritrogramas dos catetos.

O VGM encontrado foi inferior ao encontrado por Lochmiller et al. (1985a) e Santos (1999) e semelhantes ao valor encontrado por Galvez et al. (2004) e Aparício (2004). A média do CHCM foi semelhante ao encontrado por Galvez et al. (2004) e Aparício (2004), tanto para fêmea como para macho. Ao comparar com Lochmiller et al. (1985a) e Santos (1999) as médias foram semelhantes para os machos e superiores para as fêmeas.

O local de punção sanguínea recomendado por Lochmiller et al. (1984) para obtenção de amostra sanguínea em catetos é a veia cava anterior, diferente do que foi realizado neste trabalho, no qual se obteve amostra sanguínea por meio da veia cefálica. Aparício (2004) elegeu como local de punção as veias cefálica e a safena, enquanto Galvez et al. (2004) utilizou apenas a veia safena. Entretanto, mesmo com a utilização de diferentes locais de punção para obtenção de sangue, não foi observada diferenças nos valores da leucometria global obtidas nos diferentes estudos.

Com relação aos leucócitos, todos os estudos realizados encontraram resultados semelhantes para leucometria global e observaram baixos valores para monócitos e basófilos. Quanto aos eosinófilos os valores elevados encontrados por Aparício (2004) e Galvez et al. (2004) sugerem uma estimulação antigênica nas mucosas, visto o papel dos eosinófilos na resposta imune, principalmente nas helmintoses (Feldman et al. 2000; Latimer et al. 2003, Meyer \& Harvey 2004). Resultado semelhante foi obtido nos animais jovens deste estudo, provavelmente relacionada ao fato destes não terem sido vermifugados anteriormente à realização do hemograma. Nos animais adultos, observouse uma proporção de linfócitos maior do que a de neutrófilos segmentados, resultado semelhante ao encontrado por Galvez et al. (2004) e Santos (1999), e divergente em relação à Lochmiller et al. (1985a) e Aparício (2004). Esse fato provavelmente pode se dever a idade desses animais, uma vez que nos filhotes do nosso estudo, como mencionado anteriormente, foi observada uma proporção inversa aos adultos (Quadro 1), desta forma pode-se hipotetizar que este fenômeno ocorra de forma semelhante aos bovinos (Biondo et al. 1998) onde com o avançar da idade há um aumento na população de linfócitos e uma diminuição dos neutrófilos segmentados circulantes.

Em relação à mensuração das células observou-se semelhança no tamanho das células sanguíneas de vacas, gatos e cavalos, o que pode ser útil na padronização ou adaptação em uma rotina automatizada. Além disto, como todos os animais eram hígidos, estes resultados poderão subsidiar novos estudos, assim como futuras interpretações para animais hígidos ou doentes, com atenção às condições de manejo, clima e principalmente na forma de contenção e tipo de população, uma vez que diferenças foram observadas não só entre a população estudada, mas também na comparação com a literatura disponível sobre a temática.

Agradecimentos.- À Universidade Estadual de Santa Cruz, Ilhéus, $\mathrm{BA}$, pelo financiamento deste projeto.

\section{REFERÊNCIAS}

Aparício P.M.G. 2004. Fisiología reproductiva y desarrolo de métodos diagnósticos del estado reproductivo de La hembra de pecari de collar (Tayassu tajacu Linnaeus, 1758) de la Amazônia. Tese de Doutorado em Sanidade Animal, Facultat de Veterinària, Universitat Autònoma de Barcelona, Barcelona. 146p.

Batista J.S., Bezerra F.S.B., Lira R.A., Orpinelli S.R.T., Dias C.E.V. \& Oliveira A.F. 2008. Síndrome do estresse em catetos (Tayassu tajacu) submetidos à captura e contenção em diferentes horários da manhã em Mossoró, RN. Ciênc. Anim. Bras. 9:170-176.

Batista J.S., Bezerra F.S.B., Agra E.G.D., Calado E.B., Godói R.M., Nunes F.C.R. \& Blanco B.S. 2009. Efeitos da contenção física e química sobre os parâmetros indicadores de estresse em catetos (Tayassu tajacu). Acta Vet. Bras. 3:92-97.

Biondo A.W., Lopes S.T.A., Kohayagawa A., Takahira R.K. \& Alencar N.X. 1998. Hemograma de bovinos (Bos indicus) sadios da raça nelore no primeiro mês de vida, criados no estado de São Paulo. Ciência Rural 28:251-256.

Feldman F.B., Zinkl G.J. \& Jain N.C. 2000. Schalm's Veterinary Hematology. $5^{\text {th }}$ ed. Lippincott Williams and Wilkins, Baltimore. 1344p.

Flaiban K.K.M.C., Spohr K.A.H., Malanski L.S., Svoboda W.K., 
Shiozawa M.M., Hilst C.L.S., Aguiar L.M., Ludwig G., Passos F.C., Navarro I.T., Lisbôa J.A.N. \& Balarin M.R.S. 2008. Valores hematológicos de bugios pretos (Alouatta caraya) de vida livre da região do Alto Rio Paraná, Sul do Brasil. Arq. Bras. Med. Vet. Zootec. 61:628634

Furtado M.M. \& Kashivakura C.K. 2007. Artiodactyla-Tayassuidae e Suidae (cateto, queixada, javali), p.615-629. In: Cubas Z.S., Silva J.C.R. \& Catão-Dias J.L. (Eds), Tratado de Animais Selvagens: medicina veterinária. Editora Roca, São Paulo.

Galvez C.H., Montoya G.E., Nofre Sanchez P., Schettini Z.L. \& Mendoza B.P. 2004. Sanidad em el manejo del sajino (Tayassu tajacu) en el trópico. VI Congresso International sobre Manejo de Fauna Silvestre en la Amazonia y Lationamerica, 5-10 septembre, Iquitos, Peru, p.38. (Resumo)

Garcia-Navarro C.E. \& Pachaly J.R. 1994. Manual de Hematologia Veterinária. Livraria Varela, São Paulo. 169p.

Jain N.C. 1993. Essentials of Veterinary Hematology. Lea and Febiger, Philadelphia. 417p.

Lasser E.D. \& Weiser G. 2006. Laboratory technology for veterinary medicine, p.3-88. In: Thrall M.A. (Ed.), Veterinary Hematology and Clinical Chemistry. $2^{\text {nd }}$ ed. Blackwell Publishing, lowa.

Latimer K.S., Mahaffey E.A. \& Prasse K.W. 2003. Duncan and Prasse's Veterinary Laboratory Medicine: Clinical pathology. $4^{\text {th }}$ ed. Blackwell Publishing Company, lowa. 450p.

Lochmiller R.L., Hellgren E.C., Robinson R.M. \& Grant W.E. 1984. Techniques for collecting blood from collared peccaries, Dicotyles Tajacu (L.). J. Wildl. Dis. 20:47-50.
Lochmiller R.L., Hellgren E.C., Grant W.E. \& Robinson R.M. 1985a. Coccidiomycosis (Coccidioides immitis) in the collared peccary (Tayassu tajacu: Tayassuidae) in Texas. J. Wildl. Dis. 21:305-309.

Lochmiller R.L., Hellgren E.C. Varner L.W., Greene L.W., Amoss M.S., Seager S.W.J. \& Grant W.E. 1985b. Physiological responses of the adult male collared peccary, Tayassu tajacu (Tayassuidae), to severe dietary restriction. Comp. Biochem. Physiol. 82:49-58.

Madella D.A., Neto E.J.R., Felisberto M.E. \& Souza C.E. 2006. Valores hematológicos de capivaras, Hydrochoerus hydrochaeris (Rodentia: Hidrochoeridae), de vida livre na região de Campinas-SP. Ciência Rural 36:1321-1324.

Meyer D.J. \& Harvey J.W. 2004. Veterinary Laboratory Medicine: Interpretation and diagnosis. $3^{\text {rd }}$ ed. W.B. Saunders, St Louis, Missouri. $351 \mathrm{p}$.

Nogueira Filho S.L.G. \& Lavorenti A. 1995. Criação do caititu e do queixada em cativeiro. Ciência Hoje 19:6-9.

Paludo G.R., McManus C., Melo R.Q., Cardoso A.G., Mello F.P.S., Moreira M. \& Fuck B.H. 2002. Efeito do estresse térmico e do exercício sobre parâmetros fisiológicos de cavalos do exercito brasileiro. Revta Bras. Zootec. 31:1130-1142.

Reece W.O. 2006. Dukes, Fisiologia dos Animais Domésticos. $12^{\mathrm{a}}$ ed. Guanabara Koogan, Rio de Janeiro. 926p.

Santos L.C. 1999. Laboratório Ambiental. Edunioeste, Cascavel. 341p.

Sowls L.K. 1997. Javelinas and other Peccaries: Their biology, management, and use. $2^{\text {nd }}$ ed. Texas A \& M University Press, Texas. $325 p$. 